\title{
SUBSTANTIATION OF THE REPLACEMENT INTERVAL OF CONSTRUCTION MACHINES BY THE TARGET RELIABILITY LEVEL
}

\author{
Sergey Repin ${ }^{1}$, Andrej Zazykin², Natalya Krotova ${ }^{3}$ \\ 1,2,3 Saint Petersburg State University of Architecture and Civil Engineering, \\ Vtoraja Krasnoarmejskaja ul. 4, St. Petersburg, 190005, Russia.
}

${ }^{1}$ repinserge@mail.ru, ${ }^{2}$ a.v.zazykin@mail.ru, ${ }^{3}$ nata.krotova@list.ru

\begin{abstract}
The article presents results of researches in the field of ensuring operational capability of complex technical objects using the example of construction machines. Methods of determining the replacement interval of elements in accordance with the accepted at the present time progressive operating strategy - by technical condition, in accordance with the current reliability level, determined by statistical or parametric characteristics of replaced units - are considered. Replacement is performed before reaching of limiting values of characteristics. Parametric characteristics are measured in the process of unit condition diagnostics, and statistical characteristics are determined on the basis of operational information.
\end{abstract}

\section{Keywords}

Construction machines, transport-technological machines, reliability, operation, technical condition, repair.

\section{Introduction}

Provision of operational capability of complex technical objects, which include transport-technological machines (TTM), in particular, excavators, is carried out through maintenance and repair (M\&R). Since the machine life generally exceeds manifold the life of its constituent components, replacement of elements, which spent their resource, is performed during M\&R. Replacement is performed in accordance with the progressive operating strategy accepted at the present time - by technical condition (TC). TC assessment is performed based on the current reliability level which is determined by statistical or parametric characteristics of replaced units. Replacement is performed before reaching of limiting values of characteristics.

Parametric characteristics are measured in the process of unit condition diagnostics (for example, volumetric efficiency of the pump). However, not all units have measurable parameters (for example, high-pressure hoses of the hydraulic system). Such elements are replaced on the basis of statistical characteristics.

Limit values of reliability level indices and TC parameters of elements are selected taking into account the object type, its use, structural scheme of its reliability, and pattern (or determination method) of the limit state. A transportation vehicle can serve as an object type example. Let us consider two types of transportation vehicles, i.e. passenger aircraft and agricultural tractor. Failure of an important element of the aircraft in flight will lead to disaster and in the tractor - to halt in a field. Consequences of the failure differ significantly, therefore, patterns of the limit state will be different too. For the aircraft, the limit state is the probability value of the failure in flight, conditioned by safety requirements. For the tractor, the probability value of the failure is conditioned by requirements of the economic practicability of its use. The structural diagram is determined by the availability of element redundancy. In the aircraft, most systems are reserved; in the tractor - only the braking system is reserved.

Dynamics of the current values of TC parameters of elements in operation is traced through carrying out the periodic diagnostics according to the schedule of carrying out M\&R activities or through continuous diagnostics with special devices built into the operated object, and observations of the staff. Dynamics of current values of reliability level indices is assessed based on the collection of statistical information on element failures.

Planning activities on maintenance, repair and replacement of elements is carried out taking into account the operation specifics of objects. For example, 
for transport construction machines (gas pipelines) used seasonally in places, which are hard-to-reach to carry out maintenance and repair, the interval between repairs will be long. Therefore, the resource stock of machine elements prior to repair or replacement shall be increased. The scope of repair and replacement works also increases before the operation season. Such method of M\&R by the condition can be called preventive.

\section{Subject, problems and methods}

The study subject is TTM as a complex technical system consisting of elements, replacement interval of which determines the reliability of the machine as a whole.

The problem, solved in the article, is development of methods for the substantiation of the unit replacement interval. Methods of statistical analysis and forecasting are used.

\section{Assessment of machine elements reliability using the queuing theory}

Many researchers (Bujaczek, 2013; Repin and Evtjukov, 2015; Protasov and Nikolaychuk, 2011; Chernyavsky and Shadchin, 2010) propose to assess the reliability of machines with the help of the queuing theory (QT). A scheme of change in states of elements replaced by the time to failure, drawn up according to QT methods, is presented in Figure 1.

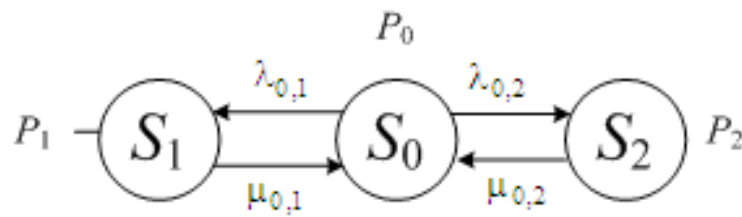

Figure 1. Marked out graph of states of the element replaced by time to failure: S - element states (S0 - operable, S1 - scheduled replacement, S2 - unscheduled replacement); $\lambda$ - failure rates; $\mu$ - repair rates; $\mathrm{P}$ - probabilities of states

Intensities of transitions between states are determined by the following equation:

$\lambda_{0 i}=\left(T_{f}\right)^{-1}, \mu_{0 i}=\left(T_{\dot{\boldsymbol{r}}}\right)^{-1}$

where $T_{f i}$ - time to $i$-th failure $(i=1$ - scheduled maintenance, $i=2$ - unscheduled maintenance); $T_{r i}$ - restoration time after $i$-th failure.

The total failure rate:

$$
\lambda=\lambda_{0.1}+\lambda_{0.2}
$$

Kolmogorov equations for the described case have the following form:

$$
\left\{\begin{array}{c}
P_{0} \lambda_{0.1}=P_{1} \mu_{1.0} \\
P_{0} \lambda_{0.2}=P_{2} \mu_{2.0} \\
P_{0}+P_{1}+P_{2}
\end{array}\right.
$$

Solving the system, we get:

$$
P_{0}=\left(1+\frac{\lambda_{0.1}}{\mu_{1.0}}\right)^{-1} ; P_{1}=P_{0} \frac{\lambda_{0.1}}{\mu_{1.0}} ; P_{2}=P_{0} \frac{\lambda_{0.2}}{\mu_{2.0}}
$$

\section{Example.}

Let the replacement interval (time between repairs $T_{s m}$ (life of a node for scheduled maintenance)) of the high pressure hose $(\mathrm{HPH})$ of the bucket hydraulic cylinder be 5,000 machine hours. ( $T_{s m}=T_{f 1}=5,000$ machine hours), replacement duration time $-0.5 \mathrm{~h}\left(T_{r 1}=0,5 \mathrm{~h}\right)$. Mean time to

failure $T_{f 2}=\bar{T}_{f}=6,500$ machine hours. Mean restoration time after the $\mathrm{HPH}$ sudden failure $-5 \mathrm{~h}\left(T_{r 2}=5 \mathrm{~h}\right)$. It is required to determine probabilities of states and the actual need for replacements.

The example solution is given in Appendix G. As a result of the calculation by equations (1-3), state probabilities are obtained:

$P_{0}=0.999, P_{1}=9.991 \cdot 10^{-5}, P_{2}=7.686 \cdot 10^{-5}$, showing a very high reliability of $\mathrm{HPH}$. This method is suitable for assessing the reliability of the machine as a system of elements, and that makes it possible to calculate such important indices of the machine as the availability factor and percentage of uptime, but does not give a proper idea of the operational reliability of elements and does not allow determination of the actual need for their replacement. For example, the operation experience shows that one of six HPHs stops operating until the scheduled date of replacement. To assess the probability of failure-free operation of the element prior to the date of its replacement, it is more preferable to use methods of the probability theory.

Determination of parameters of time-before-failure distribution laws

Deadlines of scheduled replacements are fixed according to the known resource of components. Naturally, the period of the scheduled time before component failure till the time of its replacement shall not exceed the mean time before failure (MTBF). The statistical distribution of $\mathrm{HPH}$ resource, as well as of the most of non-repairable components, is subject to the normal law. The normal law describes well the distribution of random variables at significant effect of equivalent factors. Characteristics of the normal distribution law of random variable $\mathrm{T}$ (for example, 
time to failure of a machine, node) are determined by the following expressions:

- probability distribution function:

$$
F(T)=\frac{1}{\sigma \sqrt{2 \pi}} \int_{-\infty}^{t} \exp \left(-\frac{\left(T-\bar{T}_{f}\right)^{2}}{2 \sigma^{2}} d t\right)
$$

- probability of failure-free operation:

$$
P(T)=1-F(T)
$$

- distribution density:

$$
f(t)=\frac{1}{\sigma \sqrt{2 \pi}} \exp \left(-\frac{\left(T-T_{f}\right)^{2}}{2 \sigma^{2}}\right)
$$

- root mean square deviation:

$$
\sigma=\sqrt{\frac{\sum_{i=1}^{N}\left(T_{i}-\bar{T}_{f}\right)^{2}}{N-1}}
$$

where $\bar{T}_{f}$ - mathematical expectation of a random val(5) ue (mean time to failure, average service life, etc.).

In interpretation for the considered case of HPH reliability analysis, probability distribution function $F(T)$ shows the probability of element failure before the date of its scheduled replacement.

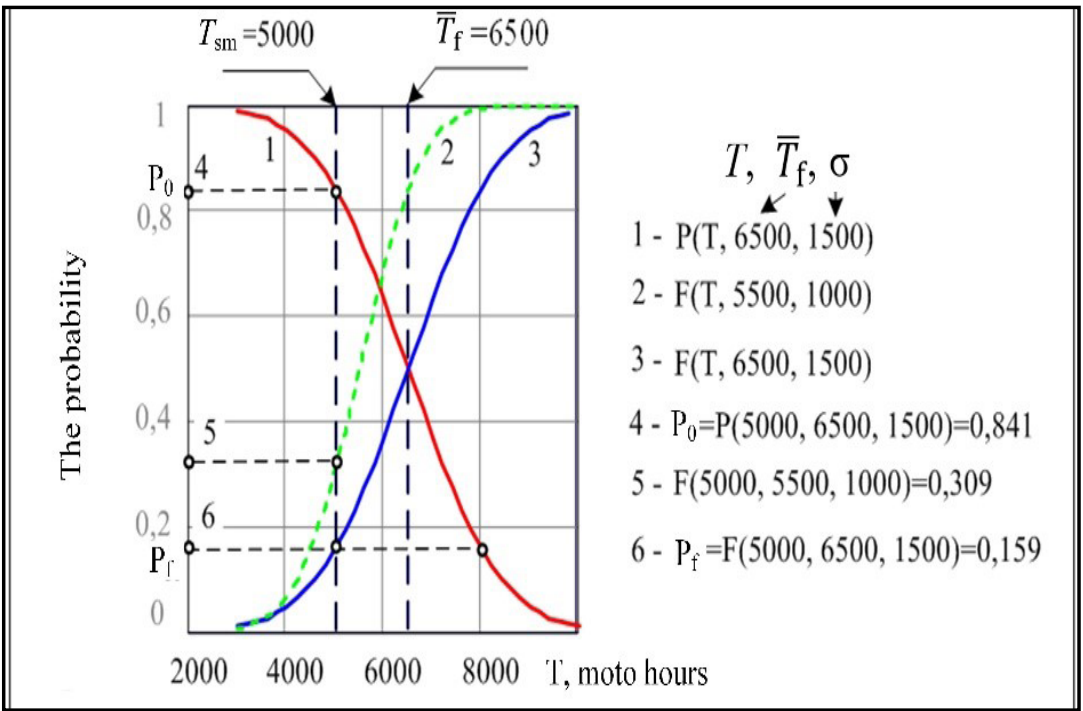

Figure 2. Graph of failure-free operation probability (line 1) and functions of HPH time-to-failure probability distribution (lines 2 and 3): $T_{s m}$ — life of a node for scheduled maintenance; $P_{0}, P f$ - probability of failure-free operation or failure of a node before the time of the scheduled repair, respectively

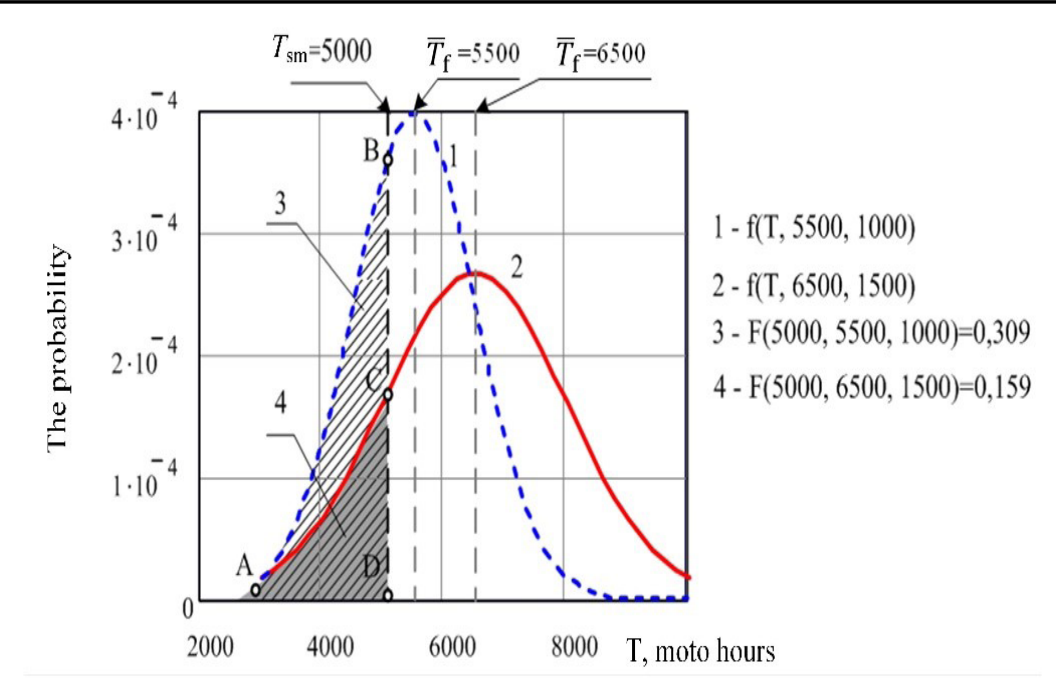

Figure 3. Graph of HPH time-before-failure probability distribution density (designations are the same as in Figure 2) 
The use of Mathcad mathematical environment significantly facilitates the work on the analysis of the operational information. Therefore, for the statistical analysis of data on time to failure, which are subject to the normal law, the Mathcad software was developed (Repin et al., 2012; Repin et al., 2016). The following statistical characteristics should be defined to determine parameters of the distribution law and construct a histogram: sample volume; minimum, maximum and mean arithmetic (mathematical expectation) sample values; root mean square deviation (Figure 2).

In Figure 3, graphs of HPH time-before-failure probabili-

ty distribution density $\mathrm{f}\left(T, \bar{T}_{f}, \sigma\right)$ are presented. Marked areas of graphs to the left of $T_{s m}$ line (figures ABD and ACD indicated with numbers 3 and 4 ) correspond to probabilities of $\mathrm{HPH}$ failure before the date of the scheduled replacement.

\section{Development of an optimization model of the num- ber of replacements by unit costs and reliability of re- placeable elements}

As the basis of probabilistic models for determination of time to failure before preventive maintenance, the idea of minimizing the weighted-average costs for repairs was laid, proposed by prof. Ye.l. Zaitsev. As weighting factors for two alternatives (emergency repair, caused by a sudden failure, and preventive repair), the risk of missing failure (Repin et al., 2012) (corresponds to $F\left(T_{s m}\right)$ ).

$$
R_{s m}=\int_{0}^{T p} f(T) d T=F\left(T_{s m}\right)=1-P\left(T_{s m}\right)
$$

and the risk of cost overrun for preventing failures (corresponds to the probability of failure-free operation):

$$
R_{p m}=\int_{T s m}^{0} f(T) d T=P\left(T_{s m}\right)
$$

are used, correspondingly, where $f(T)$ - time-to-failure

distribution density with the mathematical expectation $\bar{T}_{f}$; $T_{s m}$ - life of a node for preventive maintenance.

Costs, which are subject to minimization, are determined by the following equation:

$$
Z=Z_{s m} \cdot R_{s m}+Z_{p m} \cdot R_{p m}=Z_{s m}\left[1-P\left(T_{s m}\right)\right]+Z_{p m} \cdot P\left(T_{s m}\right) \rightarrow \text { min }
$$

where $Z_{\mathrm{sm}}$ - total costs for emergency maintenance, $Z_{\mathrm{pm}}$ - total costs for preventive maintenance.

If we express cost components through average costs of emergency $C_{s m}$ (taking into account damage $D$ - direct damage, for example, from working liquid losses and collateral to stop of works)) and preventive $C_{p m}$ maintenance, then we will obtain:

$$
Z=\frac{T_{\text {overhaul }}\left\{\left(C_{s m}+D\right) \cdot\left[1-P\left(T_{s m}\right)\right]+C_{p m} \cdot P\left(T_{s m}\right)\right.}{T_{s m}}
$$

where $T_{\text {overhaul }} / T_{s m}$ is the number of operational (repair) cycles at the specified finite time to failure $T_{\text {overhaul }}$ (for example, before the overhaul).

For a considered example, the Mathcad software is also developed. In Figure 6, results of calculating optimal element replacement intervals are presented by minimum costs in a repair cycle for various $D$ damage values.

The calculation is carried out for two types of replaceable elements of single-bucket excavators (SBE): high-pressure hoses (HPH) and bucket teeth.

Mean time to failure $\left(\bar{T}_{f}\right)$ of $\mathrm{HPH}$ is commensurable with time to failure before the overhaul $(6,500$ and 8,000 machine hours, respectively), therefore, the number of replacements in the period between repairs does not exceed two, and that reduces the demonstrative ability of some diagrams. However, for $\mathrm{HPH}$, the impact of damage, related to the sudden failure, is significant ( $D$ - up to 10,000 RUB), since in case of HPH collapse, a large amount of expensive working fluid outflows.

For bucket teeth, $\bar{T}_{f} 400-500$ machine hours, therefore, the number of replacements for elements with different reliability indices differs significantly. Figure 4 shows the effect of reliability characteristics of replaceable elements on the value of optimal element replacement intervals, calculated by minimum costs in a repair cycle. The use of this analysis method makes it possible to approach the spare parts procurement optimization from the viewpoint of "price-quality".

\section{Elements replaced according to their condition with reliability level control}

Features of operation and replacement of units:

- main reliability characteristics of elements replaced according to their condition with reliability level control are resource values of a new $T_{\text {new }}$ and replaced $T_{\text {rep }}$ units as a result of repair, characterized by time to failure in machine hours;

- the resource of the replaced (repaired) element is related to the resource of a new element through the resource restoration factor $K_{r}$ i.e. $T_{\text {rep }}=T_{\text {new }} \cdot K_{r}$ (for hydraulic actuator units, $K_{r}=0.3-0.8$;

- realization of the resource by time to failure is subject to the normal distribution law;

- dynamics of the time before failure by time is described by the exponential law $T_{f}(t)=T(1) \cdot \exp \left(-\beta_{t} \cdot t\right)$;

- distribution of the planned annual time to failure of a machine is subject to the uniform law. 


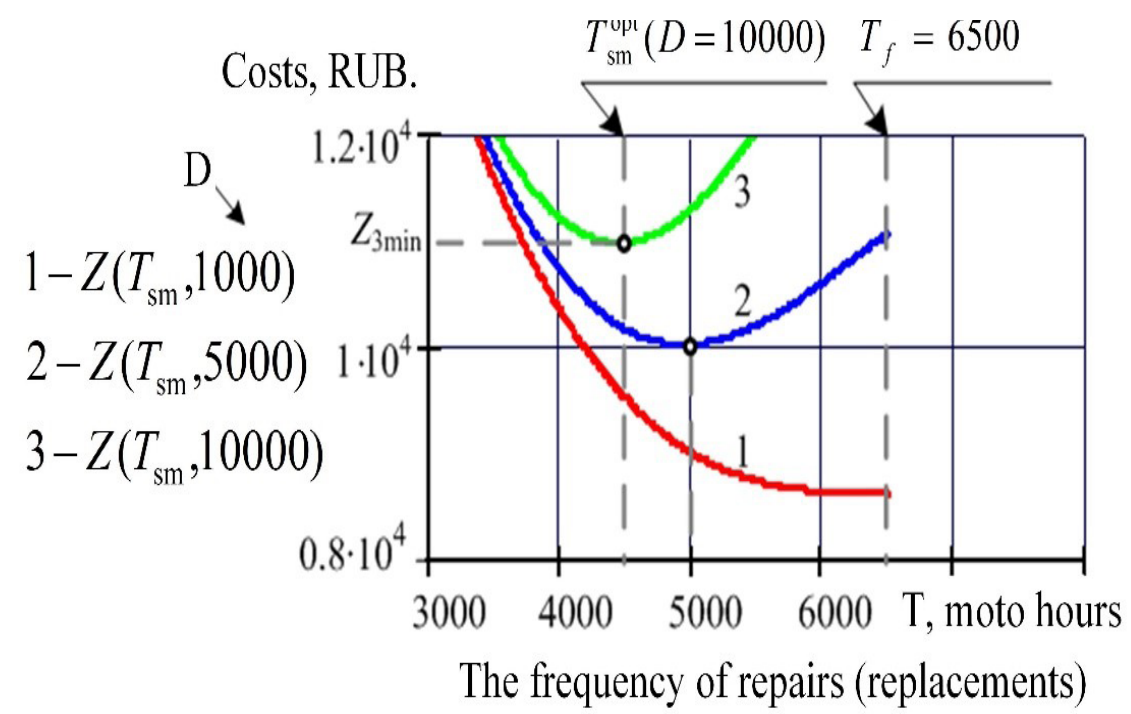

Figure 4. Results of calculating optimal element (HPH) replacement intervals by minimum costs in a repair cycle for various D damage values (RUB). $1-1000,2-5000,3-10000$

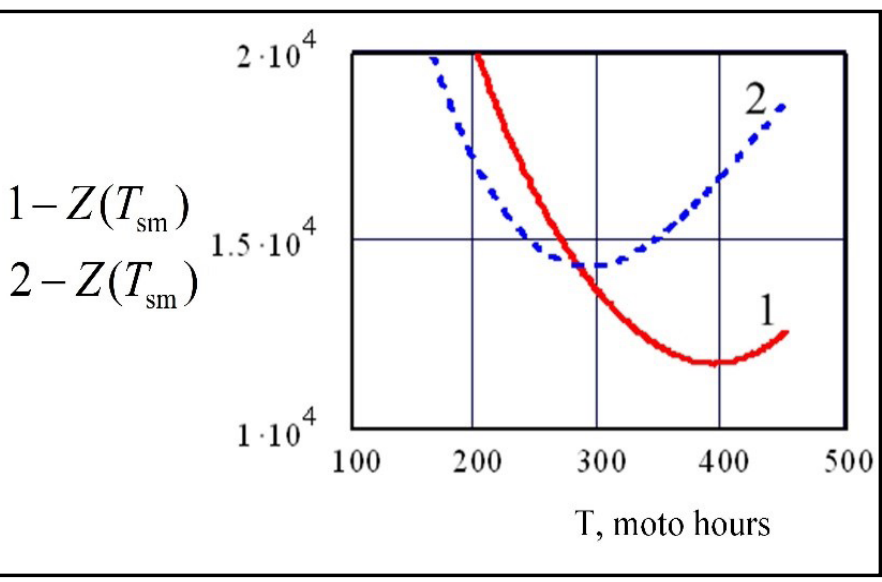

Figure 5. Effect of reliability of replaceable elements (bucket teeth) on the value of optimal element replacement intervals, calculated by minimum costs in a repair cycle (see characteristics in Table 1)

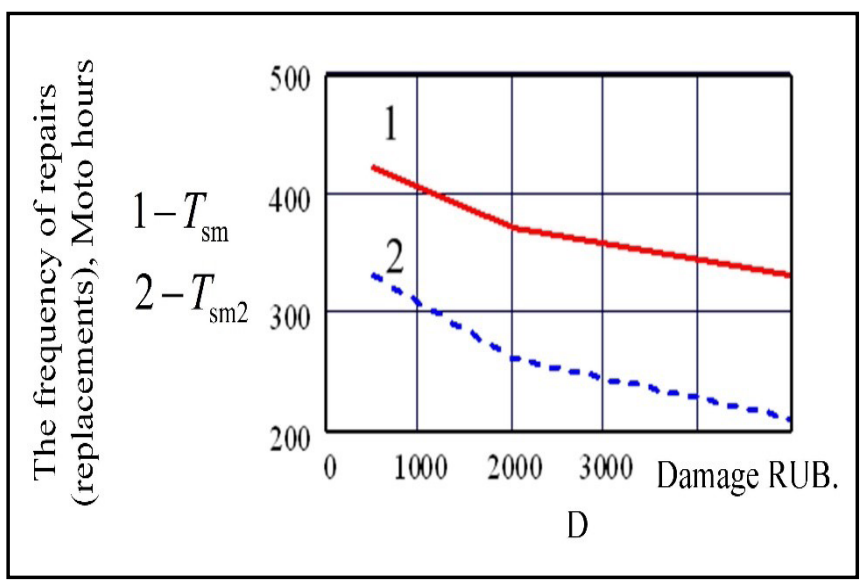

Figure 6. Effect of the damage value from sudden failures of the equipment element (tooth) and its characteristics on the value of optimal replacement intervals (using excavator tooth as an example)

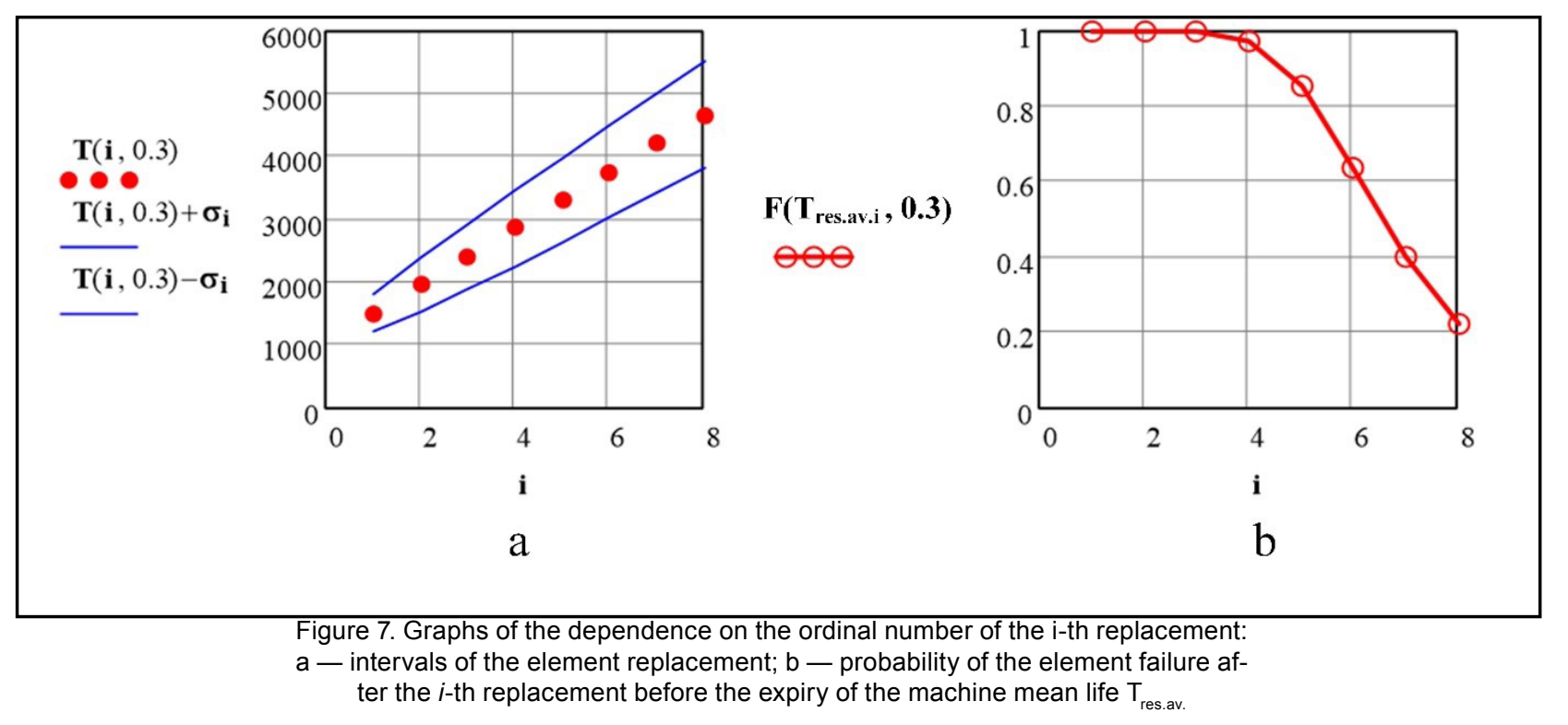


Table 1. Characteristics of the replaced element (using excavator tooth as an example)

\begin{tabular}{|l|l|l|l|l|l|}
\hline Element & $\begin{array}{c}\bar{T}_{f}, \\
\text { machine } \\
\text { hours }\end{array}$ & $\begin{array}{c}\sigma, \text { machine } \\
\text { hours }\end{array}$ & $\begin{array}{c}\mathrm{C}_{\text {pm' }}, \\
\text { RUB }\end{array}$ & $\begin{array}{c}\mathrm{C}_{\text {sm }} \\
\text { RUB }\end{array}$ & D, RUB \\
\hline No. 1 & 550 & 100 & 500 & 800 & 1,000 \\
\hline No. 2 & 450 & 120 & 400 & 700 & 1,000 \\
\hline
\end{tabular}

Determination of the replacement number of elements for the machine life taking into account the scattering of replaced element resource values

Let the average machine resource be $T_{\text {res.av. }}$. Without taking into account scattering of the element resource, the total number of necessary spare parts $n$ per one machine before writing-off will be determined by the following relation:

$Z=\frac{\left(T_{\text {res.av. }}-T_{\text {new }}\right)}{T_{\text {rep }} n}=\frac{\left(T_{\text {res.av. }}-T_{\text {new }}\right)}{T_{\text {rep }}}$

Taking into account the probable resource deviation for the normal law of its distribution, the number of spare elements is determined as follows. Let us specify the average resource before the first replacement of a particular element $T_{\text {new }}$, root mean square deviation of the resource for both new and replaced elements, $\sigma$ and resource restoration factor $K_{r}$. By the time of the first replacement the average resource will be $T_{1}=T_{\text {new }}$, by the time of the second replacement $T_{2}=T_{\text {new }}+T_{\text {rep }}=T_{\text {new }}\left(1+K_{r}\right)$, by the time of the $i$-th replacement:

$$
T_{i}=T_{\text {new }}\left[1+\mathrm{K}_{\mathrm{r}}(\mathrm{i}-1)\right]
$$

Let us assume that the root mean square deviation of the resource at all replacements of elements does not change: $\sigma 1=\sigma 2=\sigma$.

However, considering the graph of the density distribution, it is possible to note that scattering of resource values along the axis of time to failure will increase with each replacement by the value of $4 \sigma$ (Figure 11, curves 2 and 4 ).

To avoid increase in the uncertainty of the resource value after the $i$-th replacement, it is proposed (Repin and
Evtjukov, 2015) to calculate the root mean square deviation of the resource according to the following equation:

$\sigma_{i}=\sigma \sqrt{i}$

The distribution density of the new element resource $T_{\text {new }}$ and the total resource of the new and replaced elements $\left(T_{\text {new }}+T_{\text {rep }}\right)$ are represented by curves 1 and 3 . Therefore, the element failure probability at each replacement:

$$
F(T)=\phi\left\{\left(T_{\text {res.av. }}-T_{\text {new }}-T_{\text {new }} \cdot K_{r}(i-1)\right] / \sigma \sqrt{i}\right.
$$

where $F\{\ldots\}$-Laplace's function, which is determined by the table of normal distribution function values.

The total number of element replacements required for a single machine taking into account scattering of the resource:

$z=\sum_{i=1}^{8} F_{i}\left(T_{i}\right)$

Example. The life of a hydraulic actuator $T_{\text {res }}=4,000$ hours, the resource of a safety valve $T_{\text {new }}=1,500$ hours, the root mean square deviation of the resource $\sigma=300$ hours, restoration factor $K_{r}=" 0,3 . "$

The task is to determine the required number of safety valves to ensure the service life of the hydraulic actuator. The solution, fulfilled in the Mathcad program, is shown in Figure 11 and 12.

Based on the solution, shown in Figure $7 \mathrm{~b}$, the number of spare safety valves taking into account resource scattering:

$z=\sum_{i=1}^{8} F_{i} \cong 6$

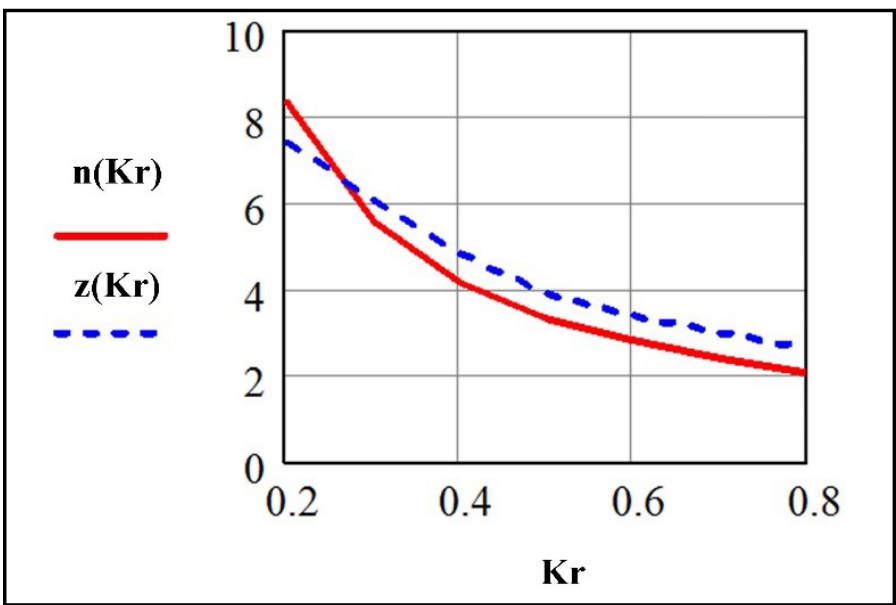

Figure 8. Graphs of the dependence of the element replacement number on the resource restoration factor $K r: n-$ without taking into account resource scattering (equation 12); $z$ - with taking into account resource scattering (equation 16) 
Sergey Repin, Andrej Zazykin, Natalya Krotova- Pages 51-60

It should be noted that the number of element replacements essentially depends on the resource restoration factor $K_{r}$. The dependence of the number of replacements $n$ and $z$ on the resource restoration factor $K_{r}$ is presented graphically in Figure 8.

To increase the value of the failure-free operation probability, it is needed to reduce the intervals of the element replacements.

Elements, replaced according to their condition with control of parameters of the technical condition

In dynamics of technical condition parameters of the machine elements, it is possible to distinguish certain features of operation and replacement of units (elements) according to their condition with control of parameters:

- in the operation process, their main parameter $X i$ characterizing the element operational capability changes;

- limit state is determined by the limiting value of the parameter $X_{\text {lim }}$;

- to predict the time to replace the element, the law of variation $X(T)$, and the limit parameter value should be known.

\section{Predicting the residual resource}

In the theory of recognition and forecasting, there are two main approaches to the problem of forecasting: probabilistic and deterministic (Repin et al., 2011; Jiang et al., 2014; Makhutov and Reznikov, 2015; Makhutov et al., 2013; Trukhanov, 2014).

Prediction of deterministic (functional) processes is carried out by interpolating (searching of the intermediate value of the function in the interval) or extrapolating (searching of the value of the function beyond the interval). In this case, at first, the analytical expression of the function under study is revealed, and then the prediction is carried out. When predicting deterministic processes with little prediction time, the Lagrange interpolating polynomial is used. When there is little information about the controlled function, the least squares method is used. Empirical formulas are used in the form of functions: fractionally linear, power, exponential, logarithmic, and others.

Example. Predicting the residual resource of the geartype pump NSh-46U based on materials of volumetric efficiency change of 20 pumps Data on the change in volumetric efficiency with time to failure are shown in Table 2.
Table 2. Data on the change in the pump volumetric efficiency with time to failure

\begin{tabular}{|c|c|c|c|c|c|}
\hline \multirow[t]{2}{*}{ Pump } & \multicolumn{5}{|c|}{ Time to failure $\mathrm{T}$, thous. $\mathrm{h}$} \\
\hline & 0.0 & 0.4 & 0.8 & 1.2 & 1.4 \\
\hline 1 & 2 & 3 & 4 & 5 & 6 \\
\hline No. 1 & 0.932 & 0.929 & 0.889 & 0.864 & 0.859 \\
\hline No. 2 & 0.945 & 0.945 & 0.925 & 0.896 & 0.866 \\
\hline No. 3 & 0.925 & 0.914 & 0.894 & 0.860 & 0.825 \\
\hline No. 4 & 0.959 & 0.966 & 0.946 & 0.921 & 0.895 \\
\hline No. 5 & 0.946 & 0.946 & 0.926 & 0.898 & 0.869 \\
\hline No. 6 & 0.941 & 0.938 & 0.918 & 0.888 & 0.858 \\
\hline No. 7 & 0.934 & 0.928 & 0.908 & 0.877 & 0.845 \\
\hline No. 8 & 0.972 & 0.968 & 0.958 & 0.934 & 0.910 \\
\hline No. 9 & 0.971 & 0.968 & 0.948 & 0.922 & 0.897 \\
\hline No. 10 & 0.955 & 0.960 & 0.940 & 0.913 & 0.887 \\
\hline No. 11 & 0.923 & 0.922 & 0.892 & 0.857 & 0.822 \\
\hline No. 12 & 0.964 & 0.962 & 0.952 & 0.928 & 0.903 \\
\hline No. 13 & 0.953 & 0.957 & 0.937 & 0.909 & 0.882 \\
\hline No. 14 & 0.943 & 0.941 & 0.921 & 0.891 & 0.861 \\
\hline No. 15 & 0.932 & 0.925 & 0.905 & 0.872 & 0.839 \\
\hline No. 16 & 0.939 & 0.925 & 0.855 & 0.814 & 0.773 \\
\hline No. 17 & 0.915 & 0.900 & 0.880 & 0.843 & 0.807 \\
\hline No. 18 & 0.935 & 0.930 & 0.910 & 0.878 & 0.846 \\
\hline No. 19 & 0.921 & 0.939 & 0.889 & 0.853 & 0.818 \\
\hline No. 20 & 0.923 & 0.921 & 0.891 & 0.856 & 0.821 \\
\hline Stand. dev. $-\sigma$ & 0.016 & 0.019 & 0.027 & 0.031 & 0.035 \\
\hline Coef. of variation & 0.017 & 0.020 & 0.030 & 0.035 & 0.041 \\
\hline $\begin{array}{l}\text { Upper level of } \\
\text { efficiency values: } \\
\text { U1 }=\eta+\sigma\end{array}$ & 0.958 & 0.958 & 0.941 & 0.915 & 0.889 \\
\hline $\begin{array}{l}\text { Average value of } \\
\text { the volumetric } \\
\text { efficiency: } \eta\end{array}$ & 0.941 & 0.939 & 0.914 & 0.884 & 0.854 \\
\hline $\begin{array}{l}\text { Lower level of } \\
\text { efficiency values: } \\
\mathrm{U} 2=\eta-\sigma\end{array}$ & 0.925 & 0.920 & 0.887 & 0.853 & 0.819 \\
\hline
\end{tabular}

Distribution of pump efficiency values at the same time to failure is subject to the normal law (Figure 9 and 10). 


\section{Architecture and Engineering Volume 2 Issue 1}

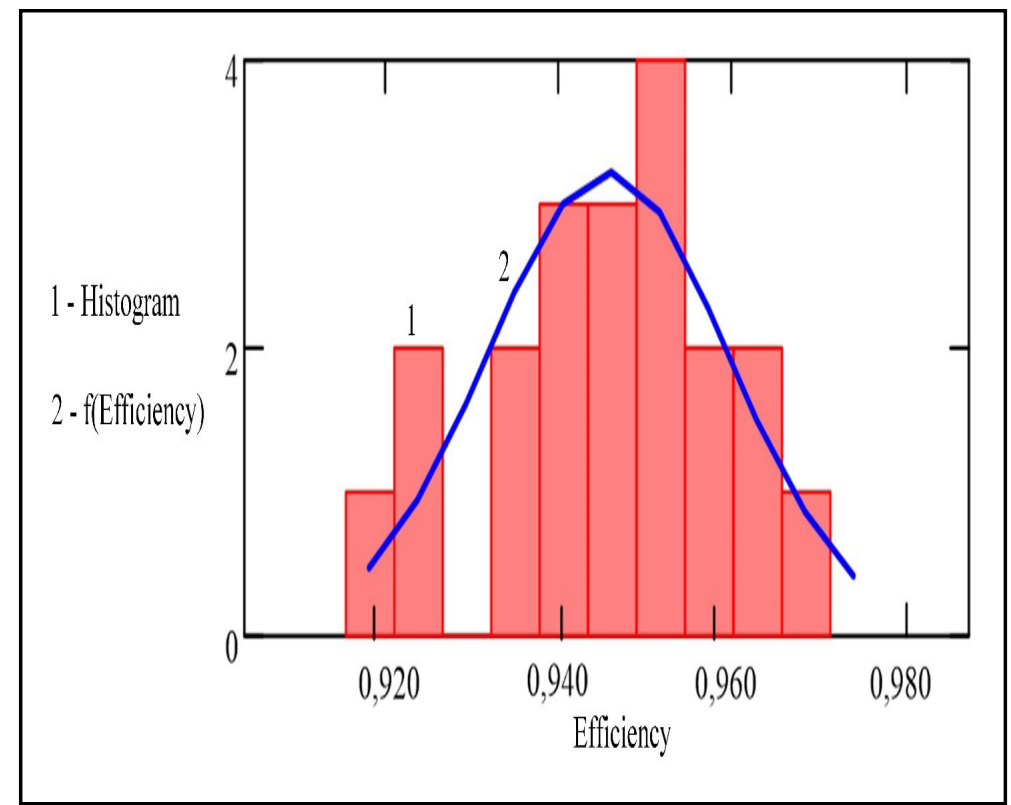

Figure 9. Histogram of the efficiency values distribution with regard to the new pump $(T=0)$ and graph of the normal distribution law density

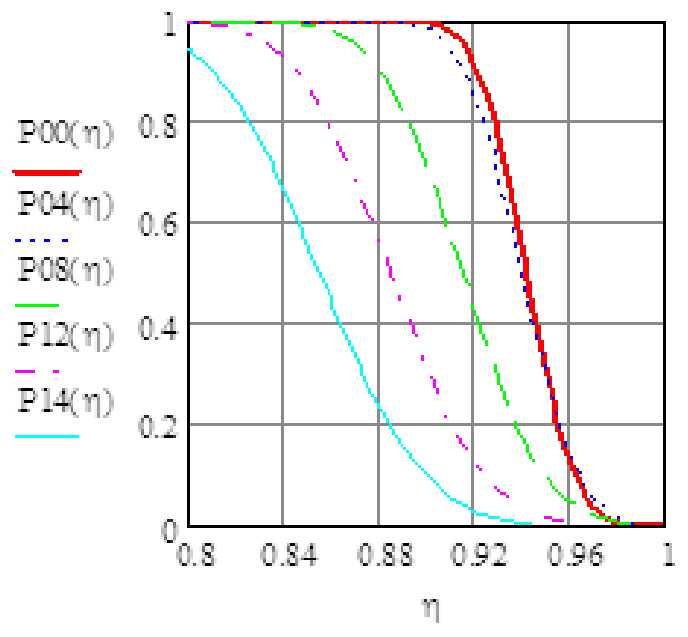

$\mathbf{a}$

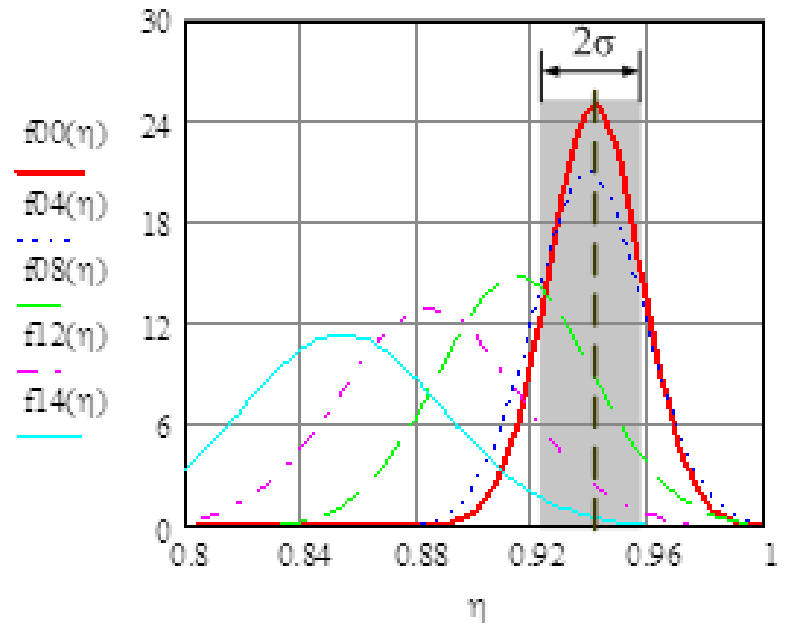

$\mathrm{b}$

Figure 10. Graphs of the dependence on time to failure: where a - probabilities of entering pump efficiency values within the interval not lower than predetermined by the curve $P(\eta)$;

$\mathrm{b}$ - densities of the normal distribution law with regard to efficiency values (in designation of probability and density, figures show time to failure in hundreds of hours) 


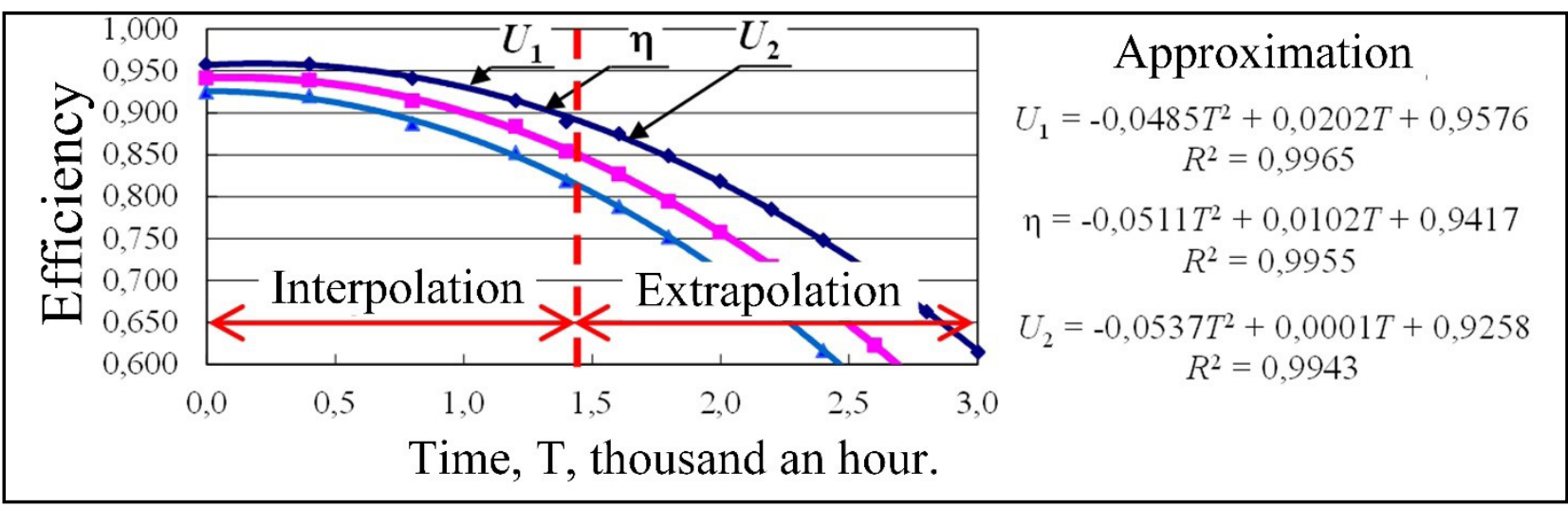

Figure 11. Results of the analysis and predicting the pump efficiency dynamics in Excel

For all 20 pumps, the averaged curve (characteristic) of the change in volumetric efficiency with time to failure $\mathrm{T}$ is constructed by finding the mathematical expectation in the middle of time-to-failure intervals (Figure 10).

Approximation of the obtained curve is made by finding parameters with the use of the least squares method and has the following form:

$\eta=a T^{2}+b T+c$

By means of this curve, prediction of efficiency values - the average value (expressions for $\eta$ ) with an interval of scattering $\pm \sigma$ (expressions for U1, U2) is performed.

\section{Acknowledgements}

The study was carried out with the financial support of the Russian Humanitarian Scientific Fund in the framework of the research project "Development of the technique of forming transport system structural elements by economic and reliability criteria (using an example of transport-technological machine fleets)", project No. 15-02-00512. 


\section{Architecture and Engineering Volume 2 Issue 1}

\section{References}

Bujaczek, R., Sławiński K., Grieger A. (2013). Agricultural machines maintenance and repair services in Western Pomerania. Technical sciences, 16(1), pp. 13-18.

Chernyavsky, A., Shadchin, A. (2010). Evaluation of reliability of low damage probability calculations for unitary structures. Journal of Machinery Manufacture and Reliability, 39(4), pp. 402-406. DOI: 10.3103/S1052618810040175

Makhutov, N., Fomin, A., Ivanov, V., Permyakov, V., Vasil'ev, I. (2013). Integrated diagnostics of limit states and early warning of emergency conditions of structures. Journal of Machinery Manufacture and Reliability, 42(2), pp 109-113. DOI: 10.3103/ S105261881302009X

Makhutov, N., Reznikov, D. (2015). Application of scenario analysis in the assessment of structural reliability of complex technical systems. Journal of Machinery Manufacture and Reliability, 44(8), pp 675-686. DOI: 10.3103/S1052618815080014

Protasov, A., Nikolaychuk, O. (2011). Applying the finite-element method for evaluating the reliability of mechanical systems. Journal of Machinery Manufacture and Reliability, 40(1), pp 27-30. DOI: 10.3103/S105261881101016X

Repin, S.V., Andronov, A.V., Zazykin, A.V. (2011). Primenenie informatsionnoi sistemy upravleniia tekhnicheskim sostoianiem transportno-tekhnologicheskikh mashin dlia opredeleniia ikh optimal'nykh srokov sluzhby [Application of the information system for technical condition management of transport-technological machines to determine their optimal life]. Automobile Engineers Journal (AAE Journal), 1, pp. 36-39. (in Russian)

Repin, S.V., Bondarenko, A.V. (2012). Optimizatsiia periodichnosti zamen uzlov transportnykh i tekhnologicheskikh mashin na osnove informatsii po dinamike parametrov ikh tekhnicheskogo sostoianiia [Periodicity optimization at replacement of transport and technological machines' units on the basis of data on dynamics of their technical condition parameters]. Vestnik grazhdanskikh ingenerov [Bulletin of Civil Engineers], 2(31), pp. 236-243. (in Russian)

Repin, S.V., Evtjukov, S.A. (2015). Renewal Methods of Construction Machinery According to Technical and Economic Indicators. Applied Mechanics and Materials, 725-726, pp. 990-995. DOI: 10.4028/www.scientific.net/AMM.725-726.990

Repin, S.V., Rulis, K.V., Zazykin, A.V., Krupin, S.A. (2012). Metodologiia obespecheniia rabotosposobnosti transportno-tekhnologicheskikh ma-shin i kompleksov sredstvami tekhnicheskoi ekspluatatsii [Methodology of ensuring operational capability of transport-technological machines and systems by technical operation means]. Saint Petersburg: SPbSUACE, 218 p. (in Russian)

Repin, S.V., Zazykin, A.V., Evtyukov, S.S. (2016). Nadezhnost' i effektivnost' transportno-tekhnologicheskikh mashin [Reliability and effectiveness of transport-technological machines]. Saint Petersburg: Petropolis Publishing House, 86 p. (in Russian)

Shao-Fei Jiang, Da-Bao Fu, Si-Yao Wu (2014). Structural Reliability Assessment by Integrating Sensitivity Analysis and Support Vector Machine. Mathematical Problems in Engineering, 2014, 6 pages. DOI: 10.1155/2014/586191.

Trukhanov, V. (2014). Mathematical model of changing the reliability level of products considering the control actions expressed in the form of probabilities. Journal of Machinery Manufacture and Reliability, 43(2), pp 124-126. DOI: 10.3103/S1052618814020186 